\title{
A gender factor in shaping T-cell immunity to melanoma
}

\author{
Roxana S. Dronca ${ }^{1}$ and Haidong Dong ${ }^{2,3}$ \\ ${ }^{1}$ Division of Medical Oncology, College of Medicine, Mayo Clinic, Rochester, MN, USA \\ ${ }^{2}$ Department of Urology, College of Medicine, Mayo Clinic, Rochester, MN, USA \\ ${ }^{3}$ Department of Immunology, College of Medicine, Mayo Clinic, Rochester, MN, USA \\ *Correspondence: dronca.roxana@mayo.edu
}

\section{Edited by:}

Cyrille J. Cohen, Bar-llan University, Israel

Reviewed by:

Jianping Huang, University of Florida, USA

Rahul Roychoudhuri, National Cancer Institute, USA

Keywords: melanoma, immunity, T-cell, sex, gender identity

\section{A commentary on}

Circulating type-1 anti-tumor CD4+ T cells are preferentially pro-apoptotic in cancer patients

by Wesa AK, Mandic M, Taylor JL, Moschos $S$, Kirkwood JM, Kwok WW, Finke JH, Storkus WJ. Front Oncol (2014). 4:266. doi: 10.3389/fonc.2014.00266

We have read with great interest the article by Wesa and colleagues in Frontiers in Oncology (1) describing the antitumor immune dysfunction in patients with melanoma and renal cell carcinoma. Accumulating evidence suggests that, in patients with cancer, the state of systemic immunity is not "normal"; rather, it is repolarized toward a state of Th2 biased "chronic inflammation," leading to suppression of cytotoxic CD8 T-cell function $(2,3)$. In this publication, the authors show that, in addition to this functional deficiency, tumor-associated antigen (TAA)-specific (but not total or viral specific) CD4+ T-cells are prone to express a pro-apoptotic phenotype in patients with active cancer. Similarly to previous reports, they show that there is evidence of immune activation in the peripheral blood of patients with advanced malignancies, manifested by increased frequencies of tumor-specific CD4+ T-cells in patients with active disease as opposed to patients rendered no evidence of disease (NED); however, these cells seems to have an enhanced sensitivity to activation-induced cell death (AICD) via an apoptotic mechanism. Interestingly, they found that female patients with melanoma had significantly higher frequencies of TAA-specific T-cells as compared to male patients, raising the possibility of sex differences in anti-tumor immunity in this disease. This is very intriguing as malignant melanoma has not classically been viewed as a hormonesensitive neoplasm; however, an accumulating body of evidence suggests that the outcome of established melanoma is influenced by endocrine status (4-6). Epidemiological studies have consistently shown that males have poorer survival rates when compared to females. Specifically, men seem to present with prognostically worse primary tumors (thicker primary melanomas with a higher incidence of ulceration), that they have a higher probability of developing metastases, and that they experience a shorter survival compared with women $(4,5)$. Possible reasons for these differences were thought to be due to differences in detection $(7,8)$, given that males are reportedly less likely to self-detect their melanomas (7), make fewer visits to health-care providers, and are less likely to engage in preventive behaviors (8). However, gender seems to remain an independent prognostic indicator even after adjustment for these factors; additionally, when disease progression takes place, women seem to progress more frequently to local sites in the form of satellite or in-transit metastases, while men exhibit more frequently direct regional lymph node metastases or show further progression to distant sites (4). It has therefore been suggested that these differences may be due to estrogen status, as data suggest that the female survival advantage may not persist after menopause $(5,6)$. We have recently analyzed data from the National Cancer Institute surveillance, epidemiology, and end results (SEER) program, including 87,165 cases of primary invasive melanoma diagnosed between 1992 and 2009 and similarly found that melanoma-specific survival was significantly poorer for males as compared to females for localized and regional disease for all age groups, suggesting that sex may influence local and regional cancer progression (9). Therefore, we postulate that a biological basis may be responsible for the consistently observed differences in clinical outcomes in patients with malignant melanoma, such as the existence of sex differences in immunity.

The sexual dimorphism in the immune system of female and male patients has long been recognized by the existence of sex differences in the incidence and course of autoimmune diseases $(10,11)$. It has been recently postulated that these immune differences could also be of relevance to the natural course and surviving chronic inflammatory conditions such as cancer. Nevertheless, the molecular differences for the sex-based differences in the outcome of malignant melanoma and other malignancies remain undefined, and, as of yet, the mechanism of this apparent female survival benefit has neither been investigated in any great depth nor have its implications been exploited with respect to therapy. In their article, Wesa et al. (1) speculate that the increased number and/or improved function of tumorspecific T-helper (Th) cells could serve as a foundation for exploring and understanding these clinical observations. Th1 cells can mediate the anti-tumor effects through a variety of mechanisms (12) and are therefore important therapeutic targets. In recent years, the Programed cell death 1 (PD-1) pathway has been found to play an important role in tumor-induced 
immune suppression (13) in melanoma and is an increasingly exploited therapeutic target in this disease and other advanced malignancies (14-16). While a role for sex-hormone modulation of PD1 has emerged, the published literature is limited to animal studies and offers conflicting findings. For instance, preclinical studies suggest that the expression and function of PD-1 are responsive to sex steroids, and that the hormone-mediated effects on PD-1 signaling pathway play important roles in mediating autoimmunity (17-19). The expression of the PD1 ligand, PD-L1, or B7-homolog 1 (B7H1) has also been shown to be modulated in an estrogen-dependent and sexdependent manner (20). One recent study examined $\mathrm{B} 7-\mathrm{H} 1$ expression on regulatory T-cells (Treg) in B-16 melanoma bearing mice. Interestingly, despite comparable B7$\mathrm{H} 1$ expression, female mice were more sensitive to PD-L1 blockade, and treatment with an anti-B7-H1 blocking monoclonal antibody reduced tumor growth to a greater degree in females compared to male mice, as a result of greater reduction in Treg function and increase in tumor-specific cytotoxic (CD8) T-cells in females (20). The reasons for this differential PD-1/B7-H1 signaling in male versus female mice are not known. Notably, there are few studies published regarding sex-hormone modulation of PD-1/B7H1 pathway in cancer, and work of this nature in humans is non-existent, despite accumulating evidence that this pathway plays a pivotal role in tumor-induced immune suppression (21). We believe that identification of sex-dependent differences in immune regulatory pathways important for immune evasion in melanoma and other advanced cancers will address an important question - whether males and females respond differently to certain immune therapies - a fact not incorporated into most clinical trial designs. Despite early successes with novel immune agents, preclinical models indicate that combinatorial therapies are likely to deliver maximum clinical impact; therefore, elucidation of the mechanisms responsible for these sex-based immune differences may identify novel treatment strategies for improving the protective aspects of T-cell immunity in malignant melanoma and other advanced malignancies.

\section{ACKNOWLEDGMENTS}

NCI R01CA134345; NIH/NIAID: R01A I095239; TR000136 NCATS/NIH.

\section{REFERENCES}

1. Wesa AK, Mandic M, Taylor JL, Moschos S, Kirkwood JM, Kwok WW, et al. Circulating type-1 anti-tumor CD4(+) T cells are preferentially proapoptotic in cancer patients. Front Oncol (2014) 4:266. doi:10.3389/fonc.2014.00266

2. Tatsumi T, Kierstead LS, Ranieri E, Gesualdo L, Schena FP, Finke JH, et al. Disease-associated bias in $\mathrm{T}$ helper type 1 (Th1)/Th2 CD4(+) T cell responses against MAGE-6 in HLA-DRB10401(+) patients with renal cell carcinoma or melanoma. J Exp Med (2002) 196(5):619-28. doi:10.1084/jem. 20012142

3. Nevala WK, Vachon CM, Leontovich AA, Scott CG, Thompson MA, Markovic SN. Evidence of systemic Th2-driven chronic inflammation in patients with metastatic melanoma. Clin Cancer Res (2009) 15(6):1931-9. doi:10.1158/1078-0432. CCR-08-1980

4. Mervic L. Time course and pattern of metastasis of cutaneous melanoma differ between men and women. PLoS One (2012) 7(3):e32955. doi:10. 1371/journal.pone.0032955

5. Mervic L, Leiter U, Meier F, Eigentler T, Forschner A, Metzler G, et al. Sex differences in survival of cutaneous melanoma are age dependent: an analysis of 7338 patients. Melanoma Res (2011) 21(3):244-52. doi:10.1097/ CMR.0b013e32834577c8

6. Kemeny MM, Busch E, Stewart AK, Menck HR. Superior survival of young women with malignant melanoma. Am J Surg (1998) 175(6):437-44. doi:10.1016/S0002-9610(98)00070-1

7. Liu W, Dowling JP, Murray WK, McArthur GA, Thompson JF, Wolfe R, et al. Rate of growth in melanomas: characteristics and associations of rapidly growing melanomas. Arch Dermatol (2006) 142(12):1551-8. doi:10.1001/archderm. 142.12.1551

8. Courtenay WH. Constructions of masculinity and their influence on men's well-being: a theory of gender and health. Soc Sci Med (2000) 50(10):1385-401. doi:10.1016/S02779536(99)00390-1

9. Dronca R, Weaver A, Brewer JD, Shuster LT, Kottschade LA, Morita SY, et al. Gender differences in survival from cutaneous melanoma: analysis of United States SEER data, 1992 to 2009. J Clin Oncol (2013) 31 (Suppl):abstr 9073.

10. Whitacre CC, Reingold SC, O'Looney PA. A gender gap in autoimmunity. Science (1999) 283(5406):1277-8. doi:10.1126/science.283.5406. 1277

11. Tengstrand B, Ahlmen M, Hafstrom I. The influence of sex on rheumatoid arthritis: a prospective study of onset and outcome after 2 years. J Rheumatol (2004) 31(2):214-22.

12. Knutson KL, Disis ML. Tumor antigen-specific $\mathrm{T}$ helper cells in cancer immunity and immunotherapy. Cancer Immunol Immunother (2005) 54(8):721-8. doi:10.1007/s00262-004-0653-2

13. Dong H, Strome SE, Salomao DR, Tamura H, Hirano F, Flies DB, et al. Tumor-associated B7-H1 promotes T-cell apoptosis: a potential mechanism of immune evasion. Nat Med (2002) 8(8):793-800. doi:10.1038/nm0902-1039c

14. Taube JM, Anders RA, Young GD, Xu H, Sharma R, McMiller TL, et al. Colocalization of inflammatory response with B7-h1 expression in human melanocytic lesions supports an adaptive resistance mechanism of immune escape. $S c i$ Transl Med (2012) 4(127):127ra37. doi:10.1126/ scitranslmed.3003689

15. Topalian SL, Hodi FS, Brahmer JR, Gettinger SN, Smith DC, McDermott DF, et al. Safety, activity, and immune correlates of anti-PD-1 antibody in cancer. N Engl J Med (2012) 366(26):2443-54. doi:10.1056/NEJMoa1200690

16. Brahmer JR, Tykodi SS, Chow LQ, Hwu WJ, Topalian SL, Hwu P, et al. Safety and activity of anti-PD-L1 antibody in patients with advanced cancer. N Engl J Med (2012) 366(26):2455-65. doi:10.1056/NEJMoa1200694

17. Wang C, Dehghani B, Li Y, Kaler LJ, Proctor T, Vandenbark AA, et al. Membrane estrogen receptor regulates experimental autoimmune encephalomyelitis through up-regulation of programmed death 1. J Immunol (2009) 182(5):3294-303. doi:10.4049/jimmunol.0803205

18. Polanczyk MJ, Hopke C, Vandenbark AA, Offner H. Estrogen-mediated immunomodulation involves reduced activation of effector $\mathrm{T}$ cells, potentiation of Treg cells, and enhanced expression of the PD-1 costimulatory pathway. J Neurosci Res (2006) 84(2):370-8. doi:10.1002/jnr.20881

19. Polanczyk MJ, Hopke C, Vandenbark AA, Offner $H$. Treg suppressive activity involves estrogendependent expression of programmed death-1 (PD-1). Int Immunol (2007) 19(3):337-43. doi:10. 1093/intimm/dxl151

20. Lin PY, Sun L, Thibodeaux SR, Ludwig SM, Vadlamudi RK, Hurez VJ, et al. B7-H1-dependent sex-related differences in tumor immunity and immunotherapy responses. J Immunol (2010) 185(5):2747-53. doi:10.4049/jimmunol.1000496

21. Keir ME, Butte MJ, Freeman GJ, Sharpe AH. PD-1 and its ligands in tolerance and immunity. Annu Rev Immunol (2008) 26:677-704. doi:10. 1146/annurev.immunol.26.021607.090331

Conflict of Interest Statement: The authors declare that the research was conducted in the absence of any commercial or financial relationships that could be construed as a potential conflict of interest.

Received: 21 November 2014; accepted: 11 January 2015; published online: 02 February 2015.

Citation: Dronca RS and Dong H (2015) A gender factor in shaping T-cell immunity to melanoma. Front. Oncol. 5:8. doi: 10.3389/fonc.2015.00008

This article was submitted to Tumor Immunity, a section of the journal Frontiers in Oncology.

Copyright (c) 2015 Dronca and Dong. This is an openaccess article distributed under the terms of the Creative Commons Attribution License (CC BY). The use, distribution or reproduction in other forums is permitted, provided the original author(s) or licensor are credited and that the original publication in this journal is cited, in accordance with accepted academic practice. No use, distribution or reproduction is permitted which does not comply with these terms. 